\title{
EDITORIAL
}

\section{Lessons from the UK National Patient Safety Agency's National Reporting and Learning System on reducing drug allergies}

Medical errors are an important cause of potentially avoidable patient harm, and there is now international interest in finding ways of reducing the disease burden resulting from iatrogenic harm. ${ }^{1} \mathrm{~A}$ key conclusion to arise from international research conducted over the last decade is the need to focus on system factors, and this has led in turn to the creation of error-reporting systems in several countries. ${ }^{2}$

Drug errors are common, and these include drug-induced allergy and anaphylaxis, many of which are likely to be preventable. ${ }^{3} \mathrm{~A}$ significant body of evidence suggests that prescribing or administering medication to which the patient has previously been identified as being allergic is one of the most common preventable medication errors in both primary and secondary care. ${ }^{4,5}$ Systems approaches can help us understand better the causes underpinning such accidental re-exposure. ${ }^{6}$

The National Reporting and Learning System (NRLS) from the UK National Patient Safety Agency (NPSA) is the world's first national database collecting information on patient safety incidents. It aims to identify trends of system failures and, through analysis of these, to devise strategies for organisational learning, thereby reducing the risk of patient harm. Its recent publication, Safety in Doses, is an important report based on the analysis of 60,000 medication-related patient safety incidents reported to the NRLS between January 2005 and June 2006. ${ }^{7}$

The report is divided into two parts, with part one summarising the findings from the analysis of incidents, and part two outlining the NPSA's Safe Medication Practice Work Programme for 2007-08. This includes five patient safety alerts outlining actions to be taken by healthcare organisations to reduce risk. The analysis showed that the majority of medication incidents relate to errors in administration. The most frequent types of incidents include administering the wrong dose, strength, or frequency of drugs, omitting medication, and administering the wrong medication. Among those patients particularly at risk for adverse events are those who have had a previously-recorded allergic reaction to certain drugs - antibiotics, opiods, and non-steroidal anti-inflammatory drugs being the drugs most frequently involved.

Based on this analysis, the NPSA has issued a number of helpful recommendations to healthcare organisations. These include the need to reassess mechanisms for documenting allergic reactions in all patient records, auditing the frequency with which these reactions occur and the extent to which they are accurately documented, and the need to increase awareness among staff about products that contain penicillin - which is frequently implicated in allergic reactions.

The major strength of this report lies in the fact that it is based on accounts of events and near-misses by UK National Health Service (NHS) employees, resulting in rich and authentic national data. The recommendations are realistic and relatively easy to implement, since they address weaknesses in the system rather than focusing on individual blame (e.g. lack of staff awareness and limitations in documenting procedures of allergy status).

Efforts now need to concentrate on implementing these suggestions locally - both in primary and secondary care and on developing and evaluating novel strategies to identify those patients most at risk of severe drug-induced allergic reactions. ${ }^{8}$

\section{Conflict of interest dedaration}

Prof Aziz Sheikh is an Assistant Editor of the PCRJ, but was not involved in the editorial review of, nor the decision to publish, this article.

\section{References}

1. Sheikh A, Baker M, Thomson R. Future Directions. In: Sandars J, Cook G, editors. ABC of Patient Safety. Oxford: Blackwell Publishing, 2007.

2. Sheikh A, Hurwitz B. A national database of medical error. J R Soc Med 1999; 92:554-5.

3. Gupta R, Sheikh A, Strachan D, Anderson HR. Increasing hospital admissions for systemic allergic disorders in England: analysis of national admissions data. BMJ 2003;327(7424):1142-3.

4. Classen DC, Pestotnik SL, Evans RS, Lloyd JF, Burke JP. Adverse drug events in hospitalized patients. Excess length of stay, extra costs, and attributable mortality. JAMA 1997;277(4):301-06.

5. Gandhi TK, Weingart SN, Borus J, Seger AC, Peterson J, Burdick E. Adverse drug events in ambulatory care. N Engl J Med 2003;348:1556-64.

6. Reason J. Human Error. Cambridge, England: Cambridge University Press, 1990. 
7. NHS National Patient Safety Agency. Safety in doses: improving the use of medicines in the NHS. Available from http://www.archive.npsa.nhs.uk/ site/media/documents/2510_Safety_in_doses_WEB.pdf. 2007.

8. Cresswell K, Sheikh A. Information technology-based approaches to reducing repeat drug exposure in patients with known drug allergies. J Allergy Clin Immunol (in press).

\section{Kathrin M Cresswell}

Research Associate

\section{*Aziz Sheikh}

Professor of Primary Care Research and Development
Allergy \& Respiratory Research Group, Division of Community Health Sciences: General Practice Section, The University of Edinburgh, 20 West Richmond Street,

Edinburgh, EH8 9DX

* Correspondence:

Tel: +44 (0)131 6514151

Fax: +44 (0)131 6509119

E-mail: aziz.sheikh@ed.ac.uk

11th January 2008

\section{Available online at http://www.thepcrj.org}

